\title{
RELAÇÃO ENTRE A TERMOGRAVIMETRIA E O ÍNDICE DE ACIDEZ DO BIODIESEL DE CANOLA E DE GIRASSOL EXPOSTOS À CONDIÇÃ̃ DE OXIDAÇÃO
}

\author{
N. S. SUVEGES ${ }^{1}$ e M. L. C. P. CAETANO ${ }^{1}$ \\ ${ }^{1}$ Universidade de São Paulo, Departamento de Engenharia Química \\ E-mail para contato: nsiktar@yahoo.com.br
}

\begin{abstract}
RESUMO - A qualidade do biodiesel quanto à oxidação durante a estocagem, é um fator importante a ser considerado, pois altas temperaturas levam a formação de ácidos graxos livres, o que pode levar a corrosão e a formação de materiais poliméricos que prejudicam todo o sistema de combustão e injeção do motor. Neste estudo as amostras foram expostas à temperatura de $60{ }^{\circ} \mathrm{C}$ (pró-oxidação) por 60 dias com o objetivo de se relacionar os valores da temperatura inicial de degradação (Ti) e do perfil termogravimétrico (TGA) com o índice de acidez. A análise da curva TGA dos biodieseis degradados apresentou a presença de 2 e 3 eventos térmicos, enquanto que o produto estável apresentou somente 1. Os biodieseis degradados também apresentaram queda de Ti quando o valor do índice de acidez aumentou e isto comprova a relação direta entre a análise termogravimétrica com o índice de acidez, o que permite concluir que ao realizar a análise termogravimétrica podese ter a constatação de um produto ácido e oxidado.
\end{abstract}

\section{INTRODUÇÃO}

O biodiesel é um combustível oriundo de fonte renovável de energia como óleos vegetais ou gorduras animais e tem sido uma alternativa para o possível esgotamento das fontes renováveis de energia, como o petróleo. Dentre as muitas características semelhantes aos dos combustíveis fósseis utilizados atualmente vale destacar que o biodiesel emite menores taxas de poluentes após combustão, apresenta viscosidade e número de cetano adequados, além é claro de poder ser utilizado nos motores a combustão dos veículos existentes.

Como muitos produtos ele possui desvantagens e dentre elas apresenta-se a menor estabilidade térmica quando comparada ao diesel, mas que pode ser alterado através da utilização de antioxidantes que prolongam seu tempo de vida útil, mas mesmo diante dessa adição e dependendo do tempo de exposição às fontes de calor, o produto está sujeito a degradação.

Uma das características de um produto oxidado é a relação com o índice de acidez. Leung, Koo e Guo (2005), estudaram o comportamento do biodiesel de canola exposto a diferentes temperaturas e na presença do ar atmosférico e relataram que quanto maior a temperatura de estocagem maior a taxa de oxidação do biodiesel e concomitantemente maior o valor do índice de acidez. Isto ocorre porque as moléculas dos ésteres metílicos de ácidos graxos se rompem durante a degradação e os ácidos 


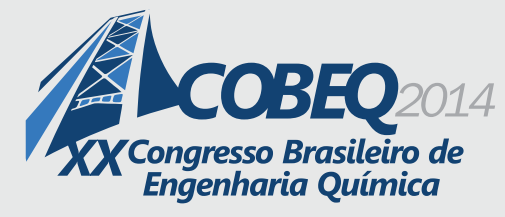

graxos livres aumentam o valor do índice de acidez.

Todas as transformações, sejam químicas ou físicas, são acompanhadas pela perda ou absorção de energia. O calor é uma forma de energia que pode acompanhar, promover, acelerar ou desacelerar processos, conforme sua intensidade e trânsito entre o sistema reagente e o ambiente. Algumas transformações envolvem ainda a variação da massa, das propriedades elétricas e mecânicas do material, e a observação de como essas variáveis se comportam à medida que a amostra é submetida ao aquecimento ou arrefecimento constitui o objeto da termoanálise (WILLARD; MERRIT Jr.; DEAN, 1974).

Nesse sentido, para a verificação da transformação ocorrida em um material, seja ela fruto de uma evaporação, degradação, oxidação ou decomposição optou-se neste estudo, trabalhar com a termogravimetria, através da qual se obtêm as curvas termogravimétricas (TGA) que são obtidas com a ajuda de termobalanças que permitem registrar diretamente a alteração de massa em função da temperatura ou do tempo. A partir da curva TGA pode-se obter também a curva DTG a qual auxilia na melhor elucidação dos resultados obtidos.

Como a termogravimetria não é uma técnica oficial para se estudar a degradação do biocombustível, recorreu-se também a análise do índice de acidez para comprovar a degradação do material, pois o índice de acidez está diretamente relacionado com o processo de oxidação. Com este trabalho surge a opção de se avaliar um biodiesel ácido e oxidado de maneira rápida, através da comparação da análise termogravimétrica do biodiesel recém-produzido com a análise do biodiesel exposto a diferentes fatores pró-oxidação.

\section{MATERIAIS E MÉTODOS}

Os biodieseis metílicos sintetizados em laboratório por catálise homogênea alcalina foram colocados em diferentes frascos de Erlenmeyer e expostos a temperatura de $60{ }^{\circ} \mathrm{C}$, notou-se que produto que sofreu degradação apresentou perfil da curva termogravimétrica e valores do índice de acidez diferentes dos produtos antes da exposição, tais diferenças principalmente observadas na curva TGA podem auxiliar na avaliação de um biodiesel de canola e girassol degradados.

\subsection{Termogravimetria (TGA)}

A termogravimetria baseia-se no estudo da variação da massa de uma amostra e é resultado de uma transformação física (sublimação, evaporação, condensação) ou química (degradação, decomposição, oxidação) em função do tempo ou da temperatura (MENDHAM et al., 2000). A temogravimetria dos biodieseis deste trabalho foi realizada em uma termobalança modelo TGA-50 marca SHIMADZU a uma taxa de aquecimento constante de $10{ }^{\circ} \mathrm{C} / \mathrm{min}$, durante o intervalo da temperatura ambiente até $600{ }^{\circ} \mathrm{C}$ e com o fluxo de ar sintético de $50 \mathrm{~mL} / \mathrm{min}$.

\section{2 Índice de acidez}

O valor do índice de acidez está diretamente relacionado à qualidade do biodiesel e serve como 
parâmetro de análise para identificação do produto degradado. Para o acompanhamento do índice de acidez dos biodieseis no decorrer dos 60 dias foi utilizada a metodologia da American Oil Chemists Society Cd 3d-63, que consiste na determinação dos ácidos graxos livres presentes no óleo e gordura e é definida com a massa de hidróxido de potássio (em miligramas) que é necessária para neutralizar os ácidos graxos livres presentes em um grama de amostra.

\section{RESULTADOS E DISCUSSÕES}

\section{1 Índice de acidez do B100 de canola e de girassol}

As amostras foram colocadas em estufa a $60{ }^{\circ} \mathrm{C}$, para se estudar o efeito da temperatura no processo de oxidação. Na Tabela 1 são observadas grandes variações do índice de acidez no decorrer do tempo de exposição.

Tabela 1 - Resultados do índice de acidez do B100 de canola e de girassol.

\begin{tabular}{cccccc}
\hline \multicolumn{5}{c}{ Índice de acidez (mg KOH/g) } \\
\hline Período & $\begin{array}{c}\text { antes da } \\
\text { exposição }\end{array}$ & 7 dias & 30 dias & 60 dias \\
B100 CANOLA & 0,10 & 0,22 & 5,04 & 16,76 \\
B100 GIRASSOL & 0,14 & 1,59 & 14,71 & 32,08
\end{tabular}

Pelos resultados apresentados fica evidente que a temperatura apresenta um caráter próoxidação intenso, nota-se a grande produção de ácidos graxos livres no B100 de canola e de girassol, a partir do $30^{\circ}$ dia, onde a amostra de canola apresenta valor do índice de acidez igual a 5,04 $\mathrm{mg}$ $\mathrm{KOH} / \mathrm{g}$ de amostra e o de girassol $14,71 \mathrm{mg} \mathrm{KOH} / \mathrm{g}$ de amostra. No $60^{\circ}$ dia o B100 de canola apresenta valor de $16,76 \mathrm{mg} \mathrm{KOH} / \mathrm{g}$ de amostra o de girassol 32,08 mg KOH/g de amostra. Estes resultados são concordantes com os observados por Leung, Koo e Guo (2005).

Assim como ocorreu para o B100 de canola exposto a temperatura de $60{ }^{\circ} \mathrm{C}$ o B100 de girassol também sofreu oxidação, mas de maneira mais rápida do que o de canola, pois logo no $7^{\circ}$ dia de exposição ao calor, observa-se alteração considerável no valor do índice de acidez $(1,59 \mathrm{mg} \mathrm{KOH} / \mathrm{g}$ de amostra) e isto pode ser justificado pelo fato de em sua composição existir maior presença de ácidos graxos insaturados o que também está relacionado a maior propensão do material de se oxidar.

\subsection{TGA do B100 de canola e de girassol}

Analisando os resultados de Ti (Tabela 2) com os resultados do índice de acidez (Tabela 1), observa-se que a Ti diminui quando o índice de acidez aumenta. 
Tabela 2 - Valores de Ti do B100 de canola e de girassol.

\begin{tabular}{ccccc}
\hline \multicolumn{5}{c}{ Valores de Ti $\left({ }^{\circ} \mathrm{C}\right)$} \\
\hline Período & $\begin{array}{c}\text { antes da } \\
\text { exposição }\end{array}$ & 7 dias & 30 dias & 60 dias \\
\hline B100 CANOLA & 201 & 200 & 193 & 188 \\
B100 GIRASSOL & 206 & 193 & 182 & 176 \\
\hline
\end{tabular}

Notou-se que as amostras com valores do índice de acidez superiores, como no caso do B100 de girassol com o valor do índice de acidez de $1,59 \mathrm{mg} \mathrm{KOH} / \mathrm{g}$ de amostra apresentou o início da formação do segundo evento térmico e valores de Ti inferior a $200{ }^{\circ} \mathrm{C}$, enquanto que as amostras com valores do índice de acidez menores apresentou um único evento térmico e valores de Ti igual ou próximos de $200{ }^{\circ} \mathrm{C}$, o que comprova que valores altos do índice de acidez tem relação direta com a degradação do biodiesel e o perfil termogravimétrico.

O perfil da curva termogravimétrica dos biodieseis apresentou os seguintes eventos térmicos no decorrer dos 60 dias: um evento térmico após 7 dias de exposição (início do $2^{\circ}$ ), 2 eventos após 30 dias e 3 eventos após 60 dias.

Das amostras que continham 2 e 3 eventos térmicos, o $2^{\circ}$ evento se iniciou em média na temperatura de $280{ }^{\circ} \mathrm{C}$ e as amostras com 3 eventos, o inicio do $3^{\circ}$ foi por volta $450{ }^{\circ} \mathrm{C}$ (temperatura em que se tem o término do $2^{\circ}$ evento térmico). Estes eventos térmicos provavelmente correspondem à decomposição dos ácidos graxos insaturados, saturados e dos produtos secundários da oxidação (como os polímeros) o que está em concordância com os estudos realizados por Chai (2012), em que relata que a energia de ativação dos ésteres metílicos insaturados são menores do que as dos ésteres metílicos saturados e consequentemente decompõem mais rápido.

Vale ressaltar que as quedas de Ti, nesta condição de aquecimento, para o B100 de girassol foram muito maiores do que para o B100 de canola, comportamento justificado pelo fato da fonte vegetal de girassol apresentar o maior número de insaturações que a fonte vegetal de canola.

Assim como foi dito anteriormente e pode ser observado na Figura 1, as amostras que apresentaram pela curva TGA, formação de mais um evento térmico, também apresentaram queda significativa nos valores de Ti. As amostras com valores do índice de acidez maiores apresentou a formação de 2 ou 3 eventos térmicos. Amostras com valores de Ti próximos aos $200{ }^{\circ} \mathrm{C}$ apresentaram um único evento térmico e menores valores do índice de acidez. 

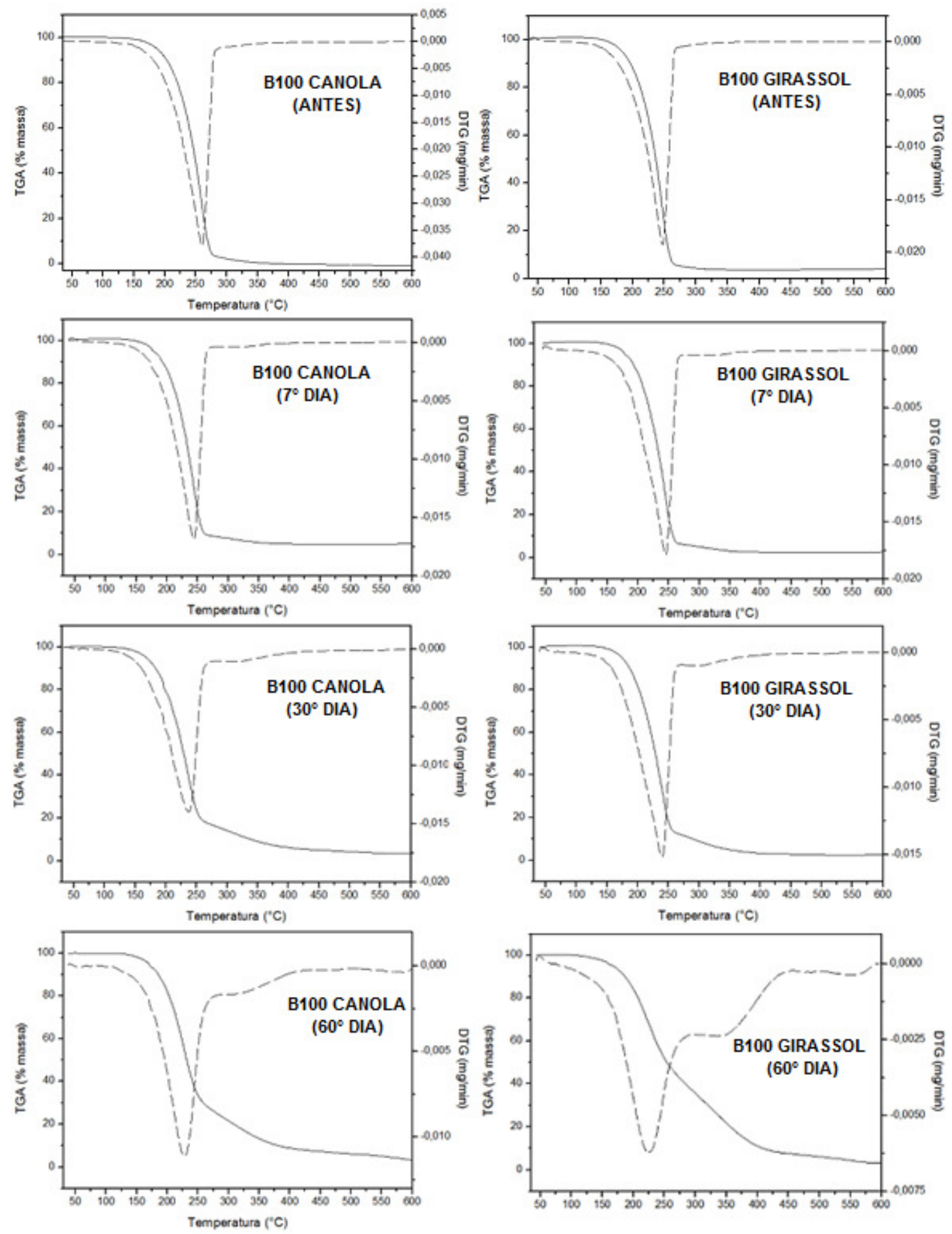

Figura 1- Perfil das curvas termogravimétricas do B100 de canola e de girassol no decorrer dos 60 dias de estudo. 
Analisando-se as curvas TGA dos biodieseis de canola e de girassol em comparação com perfil termogravimétrico dos produtos recém-produzido, é possível avaliar se o produto está ou não em boas condições para ser utilizado.

\section{CONCLUSÃO}

Em todos os casos estudados foi observado que à medida que os valores do índice de acidez aumentavam o valor de Ti diminuía;

O perfil termogravimétrico e os valores de Ti se modificam quando o produto se encontra ácido e oxidado;

A termogravimetria se apresenta como uma boa alternativa na avaliação de um produto oxidado;

\section{REFERÊNCIAS}

CHAI, M. Thermal decomposition of methyl esters in biodiesel fuel: Kinetics, Mehcanisms and Products. 193f. Tese (Doutorado em Filosofia) - Escola de Energia, Meio Ambiente, Biológicas e Engenharia Médica - Universidade de Engenharia e Ciência Aplicada. 2012.

LEUNG, D. Y. C.; KOO, B. C. P.; GUO, Y. Degradation of biodiesel under different storage conditions. Bio.Tecnho., v. 97, p. 250-256, 2006.

MENDHAM, J.; DENNEY, R. C.; BARNES, J. D.; THOMAS, M. J. K. VOGEL. Análise química quantitativa. 6. ed. Rio de Janeiro: LTC, 2012. 488p.

WILLARD, H. MERRIT Jr., L. DEAN, J. Análise Instrumental. Trad. Maria Serpados Santos. 2a ed. Fundação Kalouste Gulbenkian. Lisboa, Portugal, 1974. cap.17. 